DOI: $10.25100 /$ pfilosofica.v0i50.8652

\title{
LOS LÍMITES DEL ANTI-MAQUIAVELISMO: MEDICINA Y FILOSOFÍA EN LOS ESCRITOS TARDÍOS DE LA METTRIE (1747-1750)
}

$\left\{\begin{array}{r}\text { Adrián Ratto } \\ \text { Universidad de Buenos Aires. Consejo Nacional de Investigaciones }\end{array}\right]$

Científicas y Técnicas, Buenos Aires, Argentina.

\begin{abstract}
Resumen
En L'ouvrage de Pénélope, ou Machiavel en médecine (1748-1750), La Mettrie ataca el maquiavelismo de los médicos de su época y presenta los rasgos del médico ideal, una figura que en sus últimos escritos se confunde con la del filósofo materialista. El objetivo de este artículo es mostrar que la relación entre ambas figuras es menos simple de lo que puede parecer en un primer momento. Esto, por otra parte, pone de relieve los límites del anti-maquiavelismo de los buenos médicos. En un plano más general, el trabajo arroja algunas luces acerca de las polémicas y controversias que se produjeron en el terreno de la medicina y las ciencias de la vida en el siècle des Lumières.
\end{abstract}

Palabras clave: Siglo de las Luces; filosofí; medicina; maquiavelismo; materialismo.

Cómo citar este artículo: Ratto, A. (2020). Los límites del anti-maquiavelismo: medicina y filosofía en los escritos tardíos de La Mettrie (1747-1750). Praxis Filosófica, (50), 89-106. doi : 10.25100/ pfilosofica.v0i50.8652

Recibido: 19 de septiembre de 2019. Aprobado: 29 de octubre de 2019 


\title{
Boundaries of Anti-machiavellianism: Medicine and Philosophy in La Mettrie's Late Writings (1747-1750)
}

\author{
Adrián Ratto ${ }^{1}$
}

\begin{abstract}
In L'ouvrage de Pénélope, ou Machiavel en médecine (1748-1750), La Mettrie criticizes the Machiavellian qualities of the doctors of his time and expounds on the attributes of the ideal doctor, a figure which, in his latest work, becomes confused with that of the materialistic philosopher. This article intends to show that the connection between both figures is not as simple as it may at first appear. This, at the same time, accentuates the limits of anti-Machiavellianism in good doctors. In a more general sense, the work sheds some light on the controversies and contentions, which arose in the fields of medicine and life sciences during the siècle des Lumières.
\end{abstract}

Keywords: Enlightenment; Philosophy; Medicine; Machiavellianism; Materialism.

\footnotetext{
${ }^{1}$ Es Doctor en Filosofía por la Universidad de Buenos Aires. Actualmente se desempeña como investigador en el Consejo Nacional de Investigaciones Científicas y Técnicas (CONICET) y como jefe de trabajos prácticos en la Facultad de Filosofía y Letras de la Universidad de Buenos Aires. Su área específica de trabajo es la filosofía francesa del siglo XVIII. Entre sus últimas publicaciones se encuentran: Ratto, A. (2019). Diderot y La Mettrie, lectores de Séneca. Diánoia. Revista de Filosofía, 64(82), 115-130; Ratto, A. (2018). El lugar del filósofo en la ciudad. La figura de Sócrates en los escritos de Diderot. Contrastes. Revista Internaconal de Filosofia, 23(2), 25-40 y Ratto, A. (2016). La polémica entre Voltaire y La Beaumelle: a propósito del Supplément au Siècle de Louis XIV. Ingenium. Revista Electrónica de Pensamiento Moderno y Metodología en Historia de las Ideas, (10), 129-141.
}

ORCID: 0000-0001-6688-9533 E-mail: ga_ratto@yahoo.com.ar 


\title{
BOUNDARIES OF ANTI-MACHIAVELLIANISM: MEDICINE AND PHILOSOPHY IN LA METTRIE'S LATE WRITINGS (1747-1750)
}

\author{
Adrián Ratto \\ Universidad de Buenos Aires. Consejo Nacional de Investigaciones \\ Científicas y Técnicas, Buenos Aires, Argentina.
}

\section{Introducción}

Pese a ser calificado como uno de los máximos exponentes del materialismo del siècle des Lumières, la obra de Julien Offray de La Mettrie continúa siendo poco conocida. En efecto, como ha señalado recientemente Ann Thomson, no contamos aún con un texto de referencia acerca del conjunto de su producción, ni tampoco con una edición crítica de sus obras completas (sólo con algunas buenas ediciones de unos pocos escritos) (Thomson, 2018, pp. 313-314). Asimismo, resulta indispensable, como indica la autora, un trabajo que presente el estado actual de los estudios acerca de sus escritos, en el que se tengan en cuenta los últimos avances y las divergencias en las interpretaciones y en el que se establezca de manera fiable el conjunto de sus obras (p. 314).

Con el fin de llenar algunas de esas lagunas, el artículo propone analizar la articulación entre filosofía y medicina en los últimos escritos del médico de Saint-Malo, en particular en L'ouvrage de Pénélope, ou Machiavel en médecine (1748-50) y el Discours préliminaire (1750), dos textos sobre los que existen escasos estudios y donde el interés por la medicina se confunde con reflexiones filosóficas acerca de la relación alma-cuerpo, el carácter no natural de la moral, la política y la libertad, etc. En otras palabras, el artículo 
tiene como propósito examinar la relación que se establece en esas obras entre las figuras del médico y el filósofo, un vínculo que parece ser menos simple de lo que se puede pensar en un primer momento. El trabajo, por otra parte, arroja algunas luces acerca del carácter elitista de la filosofía de La Mettrie y en un plano más general, sobre las polémicas y controversias que tuvieron lugar en el terreno de la medicina y las ciencias de la vida en el siècle des Lumières.

La estructura del trabajo es la siguiente: en primer lugar (i), se revisan las críticas de La Mettrie a los médicos que se comportan de manera "maquiavélica", según el término utilizado por el autor, y se presentan las características que de acuerdo a él debería tener el médico ideal; luego (ii), se analizan el alcance y los límites que La Mettrie asigna al rol del filósofo en los escritos de esa época; finalmente (iii), se indaga a la luz de (i) y (ii) la problemática articulación entre medicina y filosofía, dos disciplinas que los especialistas suelen ver como indisociables en los escritos del autor de L'homme machine.

\section{La Mettrie contra los médicos de su tiempo}

En L'ouvrage de Pénélope, ou Machiavel en médecine (1748-1750) La Mettrie, que había seguido estudios de medicina en su juventud y había ejercido la profesión en Saint-Malo y en los hospitales militares de los campos de batalla, durante algunos combates de la armada de Louis XV, denuncia el "maquiavelismo" en el terreno de la medicina (La Mettrie, 1748a, pp. 9, 36) ${ }^{2}$. En efecto, en ese escrito, que publicó bajo el pseudónimo de Aletheius Demetrius entre 1748 y 1750 (dos volúmenes en 1748 y un tercero, a modo de suplemento, en 1750) en Berlín, donde había encontrado refugio tras la condena de L'Histoire naturelle de l'âme (1745) y L'homme machine (1747), ataca las artimañas del cuerpo médico de sus tiempos, más preocupados, según el autor, por la reputación y las riquezas que por la salud de la población. El trabajo de La Mettrie no es en cualquier caso un texto aislado, sino que se suma a toda una tradición literaria que representaba de manera negativa la profesión y el lenguaje de los médicos. Por no mencionar más que a unos pocos representantes de esa tradición, a los que La Mettrie alude expresamente en la obra, por cierto (La Mettrie, 1748b, pp. 28, 160, 163

\footnotetext{
${ }^{2}$ Cabe recordar que Federico II de Prusia, en cuya corte La Mettrie había encontrado protección tras la condena de sus escritos, sentía un profundo rechazo por la figura de Maquiavelo y que había escrito un Anti-Machiavel (1740), con el propósito de refutar los principios políticos del autor de $I l$ principe -el texto había sido editado por Voltaire. En los escritos tardíos de Federico II se observará, sin embargo, una cierta revalorización del maquiavelismo rechazado en su juventud.
} 
y 201), recordemos los nombres de Francesco Petrarca, Michel de Montaigne y Molière, quien ataca las prácticas de los médicos con mordacidad en su célebre Le Malade imaginaire (1673).

En la obra, que se presenta como la traducción de un diálogo entre un sabio médico oriental y su hijo, a quien éste aconseja ${ }^{3}$, La Mettrie ataca a los médicos por el uso que hacen de la medicina. Explica que estos "se detestan entre sí" y que actúan como "comerciantes", en la medida en que sólo parecen moverse en busca del "oro y la plata" (La Mettrie, 1748a, p. 146). Agrega que son individuos "viles", que para alcanzar sus propósitos saben "seducir" y "engañar" a las personas (p. 146). Cuestiona, asimismo, los errores y las lagunas en su formación (p. 41); afirma que poseen conocimientos meramente literarios y lamenta que estos doctores desdeñen saberes útiles como la anatomía, la química, la física o la cirugía.

Las críticas de La Mettrie se inscriben en un terreno, el de la medicina del siècle des Lumières, atravesado por diferentes controversias y polémicas. Entre otras, el combate entre los diferentes cuerpos que se disputaban el dominio del arte de curar, a saber, el de los médicos, el de los cirujanos, reunidos alrededor de la compañía de Saint-Côme, el de los boticarios y el de los barberos ${ }^{4}$; entre facultades: París frente a Montpellier; entre escuelas: mecanicistas frente a vitalistas, etc. Por otra parte, las competencias de unos y otros estaban mal definidas y la división entre las disciplinas era porosa $^{5}$, lo que provocó una ingente cantidad de querellas. Las disputas tuvieron que ver, asimismo, con diferencias acerca de las terapias, el modelo intervencionista de los vitalistas de Montpellier frente al menos intervencionista de los médicos de París, cuestiones éticas, como las controversias sobre la inmoralidad o no de ciertas prácticas, como, por ejemplo, la masturbación, o discusiones en torno a los efectos dañinos para la salud que podía acarrear la lectura, particularmente entre los jóvenes y las personas letradas (Vila, 2018) ${ }^{6}$.

${ }^{3}$ Esa presentación coloca al texto en el marco de una tradición literaria vinculada al cuento oriental, que atraviesa el siècle des Lumières y encuentra entre sus mojones las célebres Lettres persanes (1721) de Montesquieu y Zadig ou la Destinée (1747) de Voltaire. Véase (Perrin, 2015).

${ }^{4}$ A propósito de esta disputa en el siglo XVIII y, en un plano más general, de la constitución de la medicina como disciplina, véase (Gelfand, 1980). Véase también (French, 2003).

${ }^{5}$ Véase (Vasset, 2013). También (Wenger, 2014). Wegner señala la imposibilidad de separar en la época la medicina de la literatura y la historia (p. 328).

${ }^{6}$ Para una visión de conjunto acerca de las polémicas y controversias en torno a la medicina del siècle des Lumières, puede consultarse el dossier que dedicó en 2015 al tema ("Raconter la maladie") la revista Dix-huitème siècle ( $\left.\mathrm{n}^{\circ} 47\right)$, dirigido por Sophie Vasset y Alexandre Wenger. La revista había dedicado ya en 1991 (n²1) un dossier al asunto, "Physiologie et 
El supuesto sabio oriental de L'ouvrage de Pénélope concluye que el fin de un joven que quiera abrirse camino en el terreno de la medicina "no debe ser curar, sino triunfar, es decir, ganar dinero" (La Mettrie, 1748b, p. 167). Inmediatamente, recuerda al joven que, si tiene "libros curiosos y útiles", debe librarse de ellos y le aconseja ignorar "los nuevos descubrimientos" (p. 167) y ocultar "su espíritu, sus gustos y sus conocimientos" (p. 167). Un poco después agrega que el aspirante debe "respetar los prejuicios", particularmente con respecto a la religión (p. 169). "No seas como realmente eres [añade] (...) más que entre tus amigos. (...) en la mesa, en un círculo de amigos uno puede mofarse de los prejuicios de la sociedad, pero en público, junto a la cama de un paciente el médico debe llevar más máscaras que las que llevan los actores de la ópera Isis" (p. 172). En resumen, dice, "sed hipócrita, miserable, ladino, inescrupuloso (...) charlatán (...)" (pp. 172, 173).

No se trata, sin embargo, explica La Mettrie, de una crítica a la medicina en general. Es posible, dice, realizar un buen uso de la medicina, una práctica no maquiavélica de la misma. Ése es, precisamente, el objetivo de la segunda parte de la obra, donde opone al "maquiavelismo" un "anti-maquiavelismo" y presenta a los médicos "tal como deben ser" (La Mettrie, 1748a, Prefacio, s. p.). Allí se propone, explica, de acuerdo con el título de la obra, deshacer a partir de ese momento su propio tejido -en alusión al mito de Penélopee invertir así la imagen que había construido (La Mettrie, 1748b, p. 177). El "buen médico", indica, no es aquel que se ha dejado alcanzar por los "sistemas" o que es capaz de seducir a sus pacientes con floridos discursos, sino aquel que, formado en la "filosofía experimental", "ha amoblado su cabeza con hechos y observaciones" (p. 347). En otras palabras, el buen médico no es aquel que confunde la terapia con una retórica que poco tienen que ver con la enfermedad, sino aquel que, como el mismo La Mettrie en los hospitales militares de los campos de batalla, ha logrado observar con detenimiento los cuerpos, a través de disecciones, autopsias, etc., ha analizado su funcionamiento y es capaz de prescribir tratamientos en función de ello (Gougeaud-Arnaudeau, 2008, p. 30).

Pero, ¿puede el buen médico abandonar completamente las máscaras, los artilugios, las prácticas maquiavélicas? Para responder a esta pregunta resulta necesario examinar la relación entre la filosofía, en particular la filosofía materialista, y la sociedad, un tema que se abordará a continuación.

médecines des Lumières", dirigido en ese caso por Mirko Grmek Mirko y Roselyne Rey. Véase también (Vila, 2015). 


\section{EI filósofo en la ciudad}

En las primeras líneas de L'homme machine (1747), La Mettrie reduce los sistemas filosóficos a dos, a saber, "materialismo" y "espiritualismo" (La Mettrie, 1987a, p. 63). Todo el libro es un intento de combatir la idea de la existencia de "dos sustancias", a partir de una metodología empirista, que rechaza el conocimiento no apoyado en la experiencia (p. 118). En la conclusión afirma que "hay una única sustancia en el universo" (p. 117). Se refiere a la materia. El objeto del sabio, del buen filósofo, es, entonces, conocer la verdad, es decir, la naturaleza material del universo.

La publicación de este trabajo provocaría un seísmo en la República de las letras y obligaría a La Mettrie a abandonar Leiden y a buscar refugio en la corte de Federico II de Prusia, adonde llegó en 1748 por intermedio de su amigo Pierre-Louis Moreau de Maupertuis y donde permanecería hasta su muerte en 1751. Otro tanto puede decirse de la publicación al año siguiente, 1748, del Discours sur le bonheur, donde intenta llevar ese materialismo al terreno de la moral. El mismo Maupertuis, presidente de la Academia de Ciencias de Berlín y protector de La Mettrie, publicó en 1749 un Traité de philosophie morale, con el fin de tomar distancia de la obra de su compatriota, y Voltaire en una carta del 6 de noviembre de 1750 escrita

a Mme. Denis afirmaba que el médico francés "proscribe la virtud y los remordimientos, hace el elogio de los vicios e invita al lector a entregarse a todos los desórdenes" (Voltaire, 1880, p. 195). En un tono similar, dos años después en una carta del 27 de enero de 1752 al duque de Richelieu decía en alusión al autor del Discours que "existe una gran diferencia entre combatir la superstición de los hombres y romper los lazos de la sociedad y las cadenas de la virtud"' (Voltaire, 1832, p.14). Asimismo, el barón d'Holbach afirmaría en su célebre Système de la nature (1770) que "el autor del L'homme machine razonó sobre las costumbres como un verdadero frenético" y que, como otros ateos, "negó la distinción entre el vicio y la virtud y predicó el libertinaje" (1990, p. 339) y Denis Diderot lo atacaría con dureza en su Essai sur les règnes de Claude et de Néron, et sur les mours et les écrits de Sénèque $(1778)^{7}$. Pero, la reacción no sólo provino de personajes cercanos desde el punto de vista ideológico al médico de Saint-Malo sino también de los enemigos de les philosophes, que utilizaron la obra para mostrar a la sociedad los peligros que se desprendían de esa corriente de pensamiento ${ }^{8}$.

${ }^{7}$ A propósito de las críticas de Diderot a La Mettrie, nos permitimos mencionar nuestro reciente trabajo Autor: 2019.

${ }^{8}$ Louis-Mayeul Chaudon, por ejemplo, afirmaba en su Dictionnaire anti-philosophique (1767) que la locura y la ignorancia habían llevado a La Mettrie a despreciar los valores sagrados y que "fue uno de esos Filósofos que han diseminado en sus libros el germen de 
Los cuestionamientos, en todo caso, no carecen aparentemente de fundamentos. El mismo La Mettrie en su Discours préliminaire (1750), un trabajo que redactó a modo de introducción a sus Euvres philosophiques, que se publicaron en 1751 en Londres (en realidad, se publicaron en 1750 en Berlín), señala, en cualquier caso, que la política no tiene otro origen que el proyecto de los hombres de vivir en comunidad (La Mettrie, 1987b, p. 11). Poco después explica que la moral y ésta "no son el fruto de la naturaleza" (p. 11). A una conclusión similar había llegado en el ya mencionado Discours sur le bonheur, donde había reducido los vicios y las virtudes a meras "convenciones" y había afirmado que se podía alcanzar la felicidad, que era el fin al que aspiraba todo individuo, sin la sociedad e incluso actuando en contra de ésta (La Mettrie, 1975, p.144).

Ahora bien, La Mettrie, a pesar de reconocer las profundas diferencias entre la filosofía y la política, intenta en sus últimos trabajos, particularmente en el Discours préliminaire, mostrar que no pretende atacar los fundamentos de la sociedad. Aun cuando la filosofía llevara consigo algún peligro para la sociedad, los hombres no lograrían comprender su mensaje, dice el médico de Saint-Malo en ese trabajo: "por mucho que el materialista pruebe que el hombre no es más que una máquina el pueblo nunca lo creerá" (La Mettrie, 1987b, p. 20). De todas maneras, explica que el filósofo se ocupará de no propagar sus principios más allá de un círculo de hombres de espíritu: "en mi hogar digo lo que me parece verdadero, fuera de él digo lo que me parece útil, saludable y ventajoso. Aquí prefiero la verdad como filósofo, allá el error como ciudadano" (p. 32). En el mismo sentido agrega poco después que "no habla en el medio de la sociedad de todas esas importantes verdades filosóficas que no están hechas para la multitud" (p. 33). Por otra parte, señala la necesidad de castigar a quien se sienta inclinado a actuar contra la sociedad -aun cuando entiende que esa inclinación es natural. En efecto, afirma que esa clase de individuos es "onerosa a la sociedad", que tiene, señala, "sus armas" (leyes, verdugos, cadalsos, horcas, etc.) para responder a los agravios (La Mettrie, 1975, p. 200), y que se debe consultar el "interés público" y castigar al delincuente, "así como se debe encadenar a los locos, matar a los perros rabiosos y aplastar a las serpientes" (La Mettrie, 1975, pp. 164,165$)^{9}$.

la sedición" (pp. 211, 212). En un sentido similar, el abate Sabatier de Castres colocaría algunos años después, en 1773, la obra de La Mettrie entre "los escritos impíos, sediciosos y peligrosos para la sociedad", que consideraba que no podían tolerarse (Sabatier de Castres, 1779, pp. 106, 107).

${ }^{9}$ Se acerca en este punto a lo que Denis Diderot desarrollaría en la entrada DrOIT NATUREL, que redactó para el tomo V de la célebre Encyclopédie, publicado en 1755. Diderot señala allí 
Pero, ¿por qué defender la sociedad si el individuo no parece requerir de ella para alcanzar la felicidad? La razón del interés de La Mettrie en defender el lazo social parece encontrase en el profundo pesimismo antropológico que atraviesa el escrito, el cual ya estaba presente en trabajos anteriores: "No basta que el sabio estudie la naturaleza y la verdad; debe atreverse a decirla en beneficio del pequeño número de individuos que quieren y pueden pensar. Al resto de los hombres, que son voluntariamente esclavos de los prejuicios, les es tan difícil alcanzar la verdad, como a las ranas volar" (La Mettrie, 1987a, p. 63); "los hombres nacen en general malvados, sin la educación no habría más que unos pocos buenos y aun con ella hay más de los primeros que de los segundos" (La Mettrie, 1975, p. 139); "la razón humana es demasiado impotente" (p. 143); "máquinas mal reguladas, inclinadas hacia el mal" (p. 154); "la inclinación al mal es tan grande que es más fácil para los buenos devenir malvados que a aquellos mejorar (...). No perdamos de vista los grillos y cadenas que recibimos al nacer y que nos acompañan durante toda la vida" (p. 159); “(...) lo poco que valen los hombres en general” (p. 201); etc. De allí se desprendería la preocupación de La Mettrie por el destino de la comunidad y las conductas anti-sociales de los individuos ${ }^{10}$.

Como sugiere Ann Thomson, el autor parece heredar esa oscura concepción de la humanidad y esa actitud acomodaticia desde el punto de vista político de autores como François de La Mothe-Le-Vayer, Pierre Charron o Saint-Evremond, cuyos trabajos había leído y a quienes expresamente menciona en sus textos en numerosas ocasiones (Thomson, 1981, p. 71). Como se sabe, esos autores, a quienes se suele colocar bajo la categoría de libertinos eruditos, consideraban en general formar parte de una elite intelectual superior al resto de los hombres y eran conformistas desde el punto de vista político ${ }^{11}$.

En resumen, La Mettrie considera, no sin generar ciertas tensiones en su obra, por cierto, que el buen filósofo no debería comportarse en el medio de la sociedad como en la soledad de su escritorio o, puesto que "la filosofía solo puede comunicarse a los espíritus que ya han sido educados", junto a un círculo reducido de hombres de espíritu (La Mettrie, 1987b, p. 24).

que se debe aniquilar a aquel individuo, al que llama "razonador violento", que buscando su propio bien se opone al bien público (Diderot, 1755, pp. 115-116). Para un análisis detallado del tema, véase (Spector, 2016), especialmente el cap. 3: "Le raisonneur violent" (pp. 95-123).

${ }^{10}$ Una interpretación diferente en (Falvey, 1987). Falvey considera que La Mettrie es "optimista", en última instancia, con respecto a la naturaleza humana y el futuro de la humanidad (pp. 49, 50).

${ }^{11}$ Para una visión de conjunto sobre el tema, véase (Pintard, 1943). Acerca del elitismo en los siglos XVII y XVIII en Francia, véase (Mortier, 1969, p. 60) y ss. También (Benítez, 2003, pp. 247-259). 


\section{Utilidad de la medicina e inutilidad de la filosofía}

Frente a aquellos que reprochan a la medicina no ser más que "un saber incierto, carentes de reglas y principios, en el que todo es dudoso o directamente falso", La Mettrie va a responder en L'ouvrage de Pénélope, que quienes realizan esas acusaciones son individuos ignorantes, que no conocen el objeto que critican (La Mettrie, 1748b, p. 204). Señala que "la supuesta falta de certidumbre en el terreno de la medicina alcanza solamente a aquellos que no tienen más que un ligero conocimiento de ese arte y se disipa a medida que se avanza en los estudios" (p. 211). No se trata, añade, del saber de los médicos ordinarios, los médicos sistemáticos o los charlatanes, "pobres en experiencias y observaciones" (p. 212), sino de los verdaderos "Principios" de la medicina que se pueden encontrar, señala, en los trabajos de Hermann Boerhaave (1668-1738) -a quien expresamente menciona en numerosas ocasiones (p. 214) ${ }^{12}$ - y que hunden sus raíces en el mecanicismo cartesiano del siglo XVII. La Mettrie se refiere a la teoría iatromecanicista, según la cual la mecánica, que se puede estudiar, según el autor, mediante un método basado en la experiencia y la observación, permite explicar el funcionamiento de los organismos ${ }^{13}$. Sobre la misma base epistemológica, "experiencia" y "observación", critica a los filósofos que se pierden en especulaciones desconectadas de la naturaleza y que elevan teorías a partir de "hipótesis ininteligibles" (La Mettrie, 1987a, pp. 63, 66, 67). El buen filósofo, como el buen médico, se servirá de ese método, para poner al descubierto "los resortes ocultos" de la "máquina humana" (pp. 66, 101). La filosofía y la medicina tienen, entonces, en común el objeto, "la Naturaleza”, la materia, afirma La Mettrie (66 y La Mettrie, 1987b, p. 10).

Pero, ¿quiere esto último decir que las figuras del buen filósofo y la del buen médico se confunden, son equivalentes? No parece desprenderse

${ }^{12}$ La Mettrie tradujo al francés varios trabajos de Boerhaave, entre otros, las célebres Institutiones medicae (1708). Sobre la tarea de La Mettrie como traductor de los trabajos de Boerhaave, véase (Thomson, 1991). Acerca del papel de Boerhaave en la obra de La Mettrie, véase (Wellman, 1992), en particular el cap. 3: "Boerhaave: the Medical Heritage" (pp. 60-84).

${ }^{13}$ Ann Thomson cuestiona la relación entre la imagen de la máquina y el materialismo de La Mettrie y en un plano más general rechaza la filiación entre la filosofía de La Mettrie y Descartes (Thomson, 1998, pp. 367, 368 y 370). Argumenta, entre otras cosas, que La Mettrie no comparte la concepción de la materia de Descartes. Sostiene que mientras que en los escritos de Descartes la materia es mera extensión, es decir, una sustancia pasiva, en el caso de La Mettrie ésta tiene la capacidad de moverse, organizarse y pensar. No nos detendremos en este trabajo en las diferentes interpretaciones del materialismo de La Mettrie ni en las discusiones acerca de su filiación con la filosofía de Descartes o de Locke. Con respecto a este último tema, véase (Thomson, 2001, pp. 149-173). Existe una extensa bibliografía acerca del materialismo en el siècle des Lumières. Para una visión de conjunto sobre el tema, puede consultarse (Paschoud y Selmeci Castioni, 2019). 
esto de la obra de La Mettrie. En L'ouvrage de Pénélope intenta defenderse de aquellos que consideraban su trabajo una amenaza para las buenas costumbres y la religión, diciendo "no soy más que un médico" (La Mettrie, 1750 , p. 374) ${ }^{14}$ y antes había dicho en la parte de la obra dedicada al antimaquiavelismo que "no corresponde a un buen médico tomar partido por una religión sea ésta cual sea" (La Mettrie, 1987b, p. 271). El médico no parece comportarse como un filósofo junto a la cama del paciente. En cualquier caso, se puede observar un intento de diferenciación más elaborado entre las disciplinas en el Discours préliminaire, donde intenta separarlas en el terreno de la relación entre el conocimiento y la acción en la sociedad. La Mettrie considera que existe una conexión directa y absoluta entre la "práctica" en la sociedad del buen médico y su "teoría" (La Mettrie, 1987b, pp. 15, 16) y que es deseable que así sea, ya que su tarea junto a la cama del paciente lo convierte, exclama, en un hombre "útil" al estado (La Mettrie, 1750, p. 338). En el caso del filósofo, en cambio, no hay un vínculo directo entre la teoría y la acción en la sociedad. Éste, dice, es "un hombre ocioso, que se limita a contemplar, con los brazos cruzados, la naturaleza" (p. 338) ${ }^{15}$. Compara la relación entre ambos con la del abejorro y las abejas: "las abejas van a buscar el líquido de las plantas para llevarlo a la colmena que ellas mismas, maravillosamente, construyen ¿Para quién trabajan? Para el abejorro. Los filósofos son esos abejorros; el comerciante, el militar, el obrero, el médico, las abejas, cuyo trabajo es mucho menos recompensado que la pereza y la inutilidad de aquellos peligrosos insectos" $(338)^{16}$. Como se pudo observar en el apartado anterior, las teorías filosóficas, incluso las buenas, no afectan al estado, ya sea porque el pueblo no las comprende (La Mettrie, 1987b, pp. $15,16)$, ya sea porque el filósofo evita llevarlas al medio de la sociedad: "sean cuales sean mis especulaciones en la tranquilidad de mi gabinete, mi práctica en el mundo no se les parece" (p. 32).

${ }^{14}$ Se refiere en este caso particularmente a aquellas críticas que aparecieron en los Pensées chrétiennes (1746) de Polier de Bottens y en una nota anónima publicada en la Bibliothèque raisonnée de 1748, una revista que se publicaba fuera de Francia, en Ámsterdam, en lengua francesa. La Mettrie incorpora su respuesta en la parte final del tercer volumen de L'ouvrage de Pénélope.

${ }^{15}$ Una interpretación diferente en (Wellman, 1992). Wellman considera que el buen filósofo es un individuo engagé, algo que, según el autor, colocaría a La Mettrie más cerca de sus compatriotas que de los libertinos eruditos del siglo anterior (p. 246 y ss.).

${ }^{16}$ En el mismo sentido dice en otro pasaje de la obra: "Entre todos los filósofos el médico es el único que no es inútil y que es digno de su patria, ya que, mientras que los otros persiguen tranquilos en sus escritorios los más estériles conocimientos, él trabaja solo, sin descanso y expuesto constantemente al contagio de las enfermedades que intenta curar" (La Mettrie, 1987b, p. 186) 
De lo hasta aquí desarrollado se sigue que, a pesar de las diferencias entre filosofía y medicina, no se puede ser un buen médico sin ser al mismo tiempo un verdadero filósofo, ya que ambas disciplinas dependen del conocimiento de la naturaleza, la materia. Pero, se puede, en cambio, ser filósofo sin ser médico, en tanto el individuo permanezca en el plano de la mera contemplación, lo que lo convierte, por otra parte, en un ser inútil en el terreno social, según La Mettrie. Por esta última razón puede referirse despectivamente al filósofo, incluso al buen filósofo, el materialista, que se limita a contemplar, con los brazos cruzados, la naturaleza, y afirmar que "el médico es el único filósofo digno de su patria" (La Mettrie, 1987a, p. 62) ${ }^{17}$.

Ahora bien, si el buen médico es también un filósofo, tendrá que volver probablemente a colocarse las máscaras que había abandonado, aunque ya no como médico sino como filósofo, es decir, evitando que la filosofía altere el orden social, ya que, como se pudo observar, La Mettrie otorga al "interés público" un valor que está por encima de las especulaciones filosóficas: “¿Qué filósofo, por atrevido que sea, no reconoce, aun cuando ataque vivamente todos los principios de la moral, como yo lo he hecho en mi Anti-Sénèque, que el interés público tiene un precio diferente al de la Filosofía? La política, rodeada por todos sus ministros, va gritando en las plazas públicas, en los pulpitos e incluso en lo alto de los tejados: El cuerpo no es nada, el alma lo es todo; mortales, salvaos, cueste lo que os cueste. Los filósofos ríen, pero no perturban sus servicios" (La Mettrie, 1987b, p. 16).

La misma obra de La Mettrie ilustra esta tensión. Ésta, por un lado, pone de relieve su intento por llevar a la práctica del médico el materialismo mecanicista y la teoría empirista del conocimiento que defiende en el plano teórico, como indica Wellman (1992, p. 85 y ss). En efecto, en las primeras páginas de sus Observations de médecine pratique (1743), que recogen los casos que ha tratado como médico, señala que ese trabajo está "fundado sobre observaciones precisas y fieles" (La Mettrie, 1743, Prefacio) y que "el médico debe ser el esclavo de la Naturaleza" (15). Las enfermedades, además, tienen su origen, como en la teoría de su maestro, Boerhaave, en una ruptura del equilibrio entre los componentes de la máquina humana. Así, por ejemplo, al hablar de la histeria alude a los "desórdenes que puede sufrir nuestra máquina" y añade que la naturaleza basta para explicar todos los movimientos del cuerpo humano, incluso aquellos que como en el caso de los ataques de histeria parecen extraordinarios (p. 253) ${ }^{18}$. Por otro lado,

${ }^{17}$ De manera similar se expresa en (La Mettrie, 1987b, pp. 186 y 338).

${ }^{18}$ Gilles Barroux sostiene, en cambio, que existe una distancia entre el modelo del médico que se desprende de las obras de La Mettrie y sus propias prácticas (Barroux, 2017, pp. 123-127). 
en cambio, en los escritos donde se abordan cuestiones de orden filosófico el lector vuelve a encontrarse con las máscaras. En efecto, los textos presentan marcas que tienden a velar el sentido y a desconcertar al lector. Así, por ejemplo, critica a menudo sus propias obras, como sucede en L'ouvrage de Pénélope, donde se refiere a La Volupté, que atribuye a "M. de M...", como una obra "lasciva y peligrosa" (La Mettrie, 1748a, p. 58). También genera confusión el desorden que suelen presentar sus trabajos, algo que se puede observar claramente en el tercer volúmen de L'ouvrage de Pénélope, en donde se mezclan agregados a las otras dos partes del libro, en los que parece por momentos volver sobre sus propios pasos, con una respuesta a sus críticos y una historia ficticia del origen del libro. Asimismo, en algunos pasajes La Mettrie parece volcar sus pensamientos sobre sus escritos sin mediación, tal como su mente los concibe, un desorden, que, por otra parte, elogia en su Anti-Sénèque al hablar de la escritura de Montaigne, que no es, dice, "ni regular, ni rítmica" (La Mettrie, 1975, p. 229). Además, algunos de sus textos fueron publicados de manera anónima o atribuidos a personajes ficticios, como "M. Charp" en el caso de Histoire naturelle de l'âme, "el caballero de M." en La Volupté o "Fum-Ho-Ham" en Politique du médecin de Machiavel y en L'ouvrage de Pénélope. Finalmente, cabe mencionar la estrategia de burlarse de lo que considera verdadero, de modo tal que esto pueda destacarse, una técnica que él mismo admite y explica en el prefacio a L'ouvrage de Pénélope: "Para desenmascarar de mejor manera el vicio e inspirar más horror por él, ha sido siempre permitido arrojar algunas flores a sus pasos (...). ¿No será, entonces, de manera recíproca, un arte el burlarse de la verdad, el saber y la virtud?". Añade poco después que ese arte será su "más fino elogio [a la verdad]" y garantizará su "triunfo" (La Mettrie, 1748 a, pp. 22, 23) 19 .

Se podría objetar a esto último que, en cualquier caso, La Mettrie publicó en general sus escritos, es decir, que estos no circularon en manuscrito y de manera clandestina entre unos pocos amigos, algo que era una práctica común en el siglo XVII y comienzos del XVIII cuando se trataba de trabajos de ese tipo ${ }^{20}$. Tal vez se pueda responder que el médico de Saint-Malo no pensaba, como ya se señaló, que la escritura estuviera al alcance del pueblo:

${ }^{19}$ Ann Thomson ha analizado en detalle las estrategias retóricas y argumentativas de La Mettrie (2004, pp. 457, 458), así como los particulares problemas que el análisis de su obra plantea a los especialistas (1987, pp. 15-27).

${ }^{20}$ Como se sabe, era común en la época la censura, el encarcelamiento, la persecución de aquellos que expresaban teorías heterodoxas, etc., algo que llevaba a los autores a publicar en el extranjero, hacer circular sus escritos de manera manuscrita y clandestina u ocultar sus intenciones a través de diferentes estrategias retóricas. Véase (Paganini, 2018; Benítez, 2013). 
"él [el pueblo] no lee libros filosóficos" (La Mettrie, 1987b, p 24). Por otra parte, un poco después agrega que "no habla de la misma manera que escribe" (p. 32) ${ }^{21}$.

\section{A modo de conclusión}

Aram Vartanian afirmaba en un trabajo que tiene ya varios años que en la medida en que La Mettrie modela la figura del filósofo sobre la del médico se podría hablar de la figura ideal del "médico-filósofo" (Vartanian, 1969, p. 165) y Kathleen Wellman señalaba que el "médico ideal" es un "médico-filósofo, un hombre con conocimientos, pero también, lo que es más importante, con una amplia experiencia, que ve la medicina como el medio para curar alguna de las enfermedades de la humanidad antes que como un modo de ascenso social" (Wellman, 1992, p. 250). El verdadero filósofo, por otra parte, decía Wellman, puede detectar los problemas en la sociedad, tal como el médico lo hace con el paciente, y "ofrecer un remedio" para ello (p. 265). En un trabajo más cercano Gérard Lambert concluye que "La Mettrie lleva la medicina al corazón de la filosofía y eleva al médico al rango de filósofo" (Lambert, 2017, p. 160) ${ }^{22}$. Estas interpretaciones parecen diluir las fronteras entre los roles del médico y el filósofo en la obra de La Mettrie. Parece necesario, en cualquier caso, matizar esa interpretación, en la medida en que, como se ha visto en (iii), si bien el autor no niega que las figuras puedan coincidir, señala al menos algunas diferencias, en particular con respecto a la articulación entre la teoría y la práctica en medio de la sociedad, que lo llevan a calificar al médico como un hombre socialmente útil y al filósofo como inútil en ese terreno.

Por otra parte, con respecto a la pregunta con la que se cierra (i), se puede concluir que el buen médico, el anti-maquiavélico, no puede dejar completamente de lado las máscaras, la actitud maquiavélica, en la medida en que en tanto filósofo, que también es, no puede llevar su saber al medio de la sociedad. Allí, dado el pesimismo antropológico de La Mettrie, el filósofo debe fingir y apoyar las leyes, los castigos, los prejuicios, la religión y todo

${ }^{21}$ La cuestión de la conveniencia de la educación del pueblo cobraría mucha importancia en Prusia algunos años más tarde, a la luz del concurso de disertaciones filosóficas convocado por la Real Academia de Ciencias de Berlín sobre si era o no conveniente engañar al pueblo [“¿Puede ser útil engañar al pueblo?”]. El concurso, que tuvo lugar en 1778, fue promovido por el filósofo y matemático francés d'Alembert y auspiciado por el ya mencionado Federico II, que a pesar de comulgar con el ideario ilustrado, se inclinaría en esa época por una respuesta negativa a la cuestión.

${ }^{22}$ En un sentido similar se expresa Richard: "Medicina y Filosofía: la relación se presenta en términos de complementariedad o equivalencia" (Richard, 2006, p. 28). 
aquello que permite, según el autor, conservar el lazo social y el orden (La Mettrie, 1987b, p. 25).

Finalmente, cabe señalar que el escrito pone de relieve (ii) la actitud elitista, aristocratizante de La Mettrie, que hace difícil incluirlo entre lo que Jonathan Israel denomina ilustración radical, en la última gran suma acerca de la filosofía del siglo XVIII. Israel considera que la tendencia democrática, igualitaria, es una de las principales características de aquellos que representarían esa corriente (Israel, 2001, p. 21). Resulta por lo tanto difícil incluir en esa categoría a La Mettrie, aunque Israel considera que es junto a Denis Diderot uno de sus máximos representantes (p. 704) ${ }^{23}$. Pero, en cualquier caso, el análisis de las tesis de Israel, que, cabe señalar, han dado un importante impulso a los estudios sobre el siglo XVIII en los últimos años, es algo que excede los límites de este trabajo ${ }^{24}$.

\section{Referencias bibliográficas}

Bahr, F. (2016). Jonathan Israel y la revisión de la historiografía moderna desde el concepto de Ilustración radical. En S. Manzo y V. Waksman. (Eds.), ¿Por qué seguir contando historias de la filosofía? (pp. 135-147). Buenos Aires, Argentina: Prometeo.

Barroux, G. (2017). La Mettrie médecin, envers et contre tous. En A. Paschoud y F. Pépin. (Eds.), La Mettrie: philosophie, science et art d'écrire (pp. 111-129). París, Francia: Éditions Matériologiques.

Benítez, M. (2003). Luces y elitismo en los manuscritos clandestinos. En M. Benítez. (Ed.), La cara oculta de las Luces. Investigaciones sobre los manuscritos filosóficos clandestinos de los siglos XVII y XVIII (pp. 247-259). Valencia, España: Biblioteca Valenciana.

Benítez, M. (2013). Le Foyer clandestin des Lumières. Nouvelles recherches sur les manuscrits clandestins. París, Francia: Honoré Champion.

Chaudon, L.-M. (1767). Dictionnaire anti-philosophique. Aviñón, Francia: Girard y Seguin.

Diderot, D. (1755). Droit naturel. En D. Diderot y J.-L. d'Alembert. (Eds.), Encyclopédie ou Dictionnaire raisonné des sciences, des arts et des métiers par une société des gens de lettres [Vol. 5.] (pp. 115-116). París, Francia: Briasson. Falvey, J. (1987). La Politique textuelle du Discours préliminaire: 1'anarchisme de La Mettrie. Corpus, (5/6), 27-61.

French, R. (2003). Medicine Before Science: The Business of Medicine from the Middle Ages to the Enlightenment. Cambridge, Inglaterra: Cambridge University Press.

${ }^{23} \mathrm{El} \mathrm{mismo} \mathrm{Israel} \mathrm{parece} \mathrm{revisar} \mathrm{su} \mathrm{interpretación} \mathrm{algunos} \mathrm{años} \mathrm{más} \mathrm{tarde,} \mathrm{véase} \mathrm{(Israel,}$ 2006, p. 804).

${ }^{24}$ Sobre este tema, véase (Lilti, 2009; Bahr, 2016). 
Gelfand, T. (1980). Professionalizing modern medicine: Paris surgeons and medical science and institutions in the 18th century. Westport, EUA: Greenwood Press.

Gougeaud-Arnaudeau, S. (2008). La Mettrie (1709-1751), le matérialisme clinique. París, Francia: L'Harmattan.

Holbach, P. (1990). Système de la nature ou des lois du monde physique et du monde moral. París, Francia: Fayard.

Israel, J. (2001). Radical Enlightenment. Philosophy and the Making of Modernity 1650-1750. Oxford: Oxford University Press.

Israel, J. (2006). Enlightenment Contested: Philosophy, Modernity, and the Emancipation of Man, 1670-1752. Oxford, Inglaterra: Oxford University Press.

La Mettrie, J.-O. (1743). Observations de médecine pratique. París, Francia : Huart.

La Mettrie, J.-O. (1748a). L'ouvrage de Pénélope, ou Machiavel en médecine [vol. 1]. Berlín, Alemania: Cramer \& Ph. Philibert.

La Mettrie, J.-O. (1748b). L'ouvrage de Pénélope, ou Machiavel en médecine [vol. 2]. Berlín, Alemania: Cramer \& Ph. Philibert.

La Mettrie, J.-O. (1750). L'ouvrage de Pénélope, ou Machiavel en médecine [vol. 3]. Berlín, Alemania: Cramer \& Ph. Philibert.

La Mettrie, J.-O. (1975). Discours sur le bonheur. Oxford, Inglaterra: Voltaire Foundation.

La Mettrie, J.-O. (1987a). L'homme-machine. En CEuvres philosophiques [Vol. 1]. París, Francia: Fayard.

La Mettrie, J.-O. (1987b). Discours préliminaire. En CEuvres philosophiques [Vol. 1]. París, Francia: Fayard.

Lambert, G. (2017). La Mettrie, médecin par-delà le miroir et les simulacres. En A. Paschoud y F. Pépin. (Eds.), La Mettrie: philosophie, science et art d'écrire (pp. 129-160). París, Francia: Éditions Matériologiques.

Lilti, A. (2009). Comment écrit-on l'histoire intellectuelle des Lumières: Spinozisme, radicalisme et philosophie. Annales. Histoire, Sciences Sociales, 64(1), 171-206.

Mortier, R. (1969). Ésotérisme et Lumières. Un dilemme de la pensée du XVIIIe siècle. Ginebra, Suiza: Droz.

Paganini, G. (2018). Enlightenment before the Enlightenment: Clandestine Philosophy. Etica e Politica, 20, 183-200.

Paschoud, A. y Selmeci Castioni, B. (Eds.) (2019). Matérialisme(s) en France au XVIIIe siècle. Entre littérature et philosophie. Berlín, Alemania: Frank y Timme.

Perrin, J.-F. (2015). L'Orientale allégorie. Le conte oriental au XVIII e siècle en France (1704-1774). París, Francia : Honoré Champion.

Pintard, R. (1943). Le Libertinage érudit dans la première moitié du XVIIe siècle. París, Francia: Boivin.

Richard, J. (2006). Médecine, physique et métaphysique dans les oeuvres philosophiques de La Mettrie. En S. Audidière et al. (Eds.), Matérialistes français du XVIIIe siècle (pp. 21-43). París, Francia: Presses Universitaires de France. 
Sabatier de Castres, A. (1779). Les trois siècles de la littérature française, ou Tableau de l'esprit de nos écrivains, depuis François I, jusqu'en 1773 [Vol. 3]. París, Francia: Moutard.

Spector, C. (2016). Éloges de l'injustice. La philosophie face à la déraison. París, Francia: Seuil.

Thomson, A. (1981). Materialism and society in the mid-eighteenth century: La Mettrie's Discours préliminaire. París, Francia: Droz.

Thomson, A. (1987). La Mettrie ou la machine infernale. Corpus, 5/6, 15-27.

Thomson, A. (1991). La Mettrie, lecteur et traducteur de Bœrhaave. Dix-huitième Siècle, 23, 23-29.

Thomson, A. (1998). L'homme-machine: mythe ou métaphore? Dix-huitième siècle, 20, 367-376.

Thomson, A. (2001). Materialistic Theories of Mind and Brain. En W. Lefèvre. (Ed.), Between Leibniz, Newton, and Kant (pp. 149-173). Boston, EUA: Kluwer Academic Publishers.

Thomson, A. (2004). La Mettrie, l'écrivain et ses masques. Dix-huitième Siècle, $36,449-467$.

Thomson, A. (2018). La Mettrie. Philosophie, science et art d'écrire, sous la direction d'Adrien Paschoud et François Pépin. Recherches sur Diderot et sur l'Encyclopédie, 53, 313-315.

Vartanian A. (1969). Le philosophe selon La Mettrie. Dix-huitième Siècle, 1, 161-178.

Vasset, S. (2013). Medicine and Narration in the Eighteenth Century. Oxford, Inglaterra: Voltaire Foundation.

Vila, A. (2015). Medicine and the body in the French enlightenment. En D. Brewer. (Ed.), The Cambridge Companion to the French Enlightenment (pp. 199-213). Cambridge, Inglaterra: Cambridge University Press.

Vila, A. (2018). Suffering Scholars: Pathologies of the Intellectual in Enlightenment France.Filadelfia, EUA: University of Pennsylvania Press.

Voltaire. (1832). À M. le Maréchal Duc de Richelieu. En M. Beuchot. (Ed.), Euvres de M. Arouet de Voltaire (pp. 14-16). París, Francia: Lefèvre - Firmin Didot Frères.

Voltaire. (1880). Lettre 2143. À Madame Denis. En L. Moland. (Ed.), Euvres complètes de Voltaire (pp. 194-195). París, Francia: Garnier.

Wellman, K. (1992). La Mettrie: Medicine, Philosophy and Enlightenment. Londres, Inglaterra: Duke University Press.

Wenger, A. (2014). Médecine, littérature, histoire. Dix-huitième Siècle, 46, 323-336. 
